\title{
Estratégia Clínico-Interpretativa: Um Recurso à Pesquisa Psicanalítica
}

\author{
Carolina Neumann de Barros Falcão Dockhorn ${ }^{1}$ \\ Mônica Medeiros Kother Macedo \\ Pontifícia Universidade Católica do Rio Grande do Sul
}

\begin{abstract}
RESUMO - A Psicanálise impôs uma ruptura fundamental em relação à noção de ciência, demandando ampliação na concepção de método. A prática de pesquisa psicanalítica encontra na academia um cenário propício ao exercício de rigor e de criatividade do psicanalista. Reconhecendo divergências na pesquisa em psicanálise, a respeito da possibilidade investigativa além da clínica psicanalítica, este artigo apresenta uma estratégia de investigação com o método psicanalítico. Propõe-se a estratégia clínico-interpretativa que, sustentada na especificidade e no rigor psicanalítico, toma a escuta, a abstinência, a transferência e a interpretação como alicerces na pesquisa e na produção de conhecimento em psicanálise. Esta estratégia é composta de três etapas, as quais visam à interpretação e à ampliação de significados de um dado fenômeno.
\end{abstract}

Palavras-chave: psicanálise, pesquisa, método, estratégia clínico-interpretativa

\section{Clinical-Interpretative Strategy: APsychoanalytical Research Tool}

\begin{abstract}
Psychoanalysis has imposed a fundamental break with the notion of science, demanding an expansion of the conception of method. The practice of psychoanalytical research has a favorable setting in academic context regarding the possibility of a rigorous and creative practice of the psychoanalyst. Recognizing the controversies in psychoanalytical research regarding the possibilities of investigation beyond the psychoanalytical clinic, this paper presents a research strategy based on the psychoanalytic method. This is the clinical-interpretative strategy, sustained on the specificities and rigor of psychoanalysis, which establishes listening, abstinence, transference and interpretation as the building blocks of research and production of knowledge in psychoanalysis. This strategy is composed by three steps, which aim the interpretation and the expansion of the meaning of a phenomenon.
\end{abstract}

Keywords: psychoanalysis, research, method, clinical-interpretative strategy

É inquestionável a revolução incitada pelas proposições freudianas nas concepções vigentes da ciência moderna. Certamente, as tensões que se estabeleceram entre as noções de ciência e de método científico com a psicanálise mantêmse até hoje, principalmente sob o questionamento acerca de ser a última uma ciência ou não. Tentando lançar luz a essa discussão, Lo Bianco (2003) demonstra o quanto Freud apropriou-se do método científico ao longo de sua formação acadêmica e de seus trabalhos no Laboratório de Fisiologia e depois no Hospital Geral e constata que não foi por falta de habilidade com a pesquisa empírica que Freud enveredou por outro caminho. Ao tomar o inconsciente como objeto de investigação, Freud logo percebeu a impossibilidade de estudá-lo a partir das concepções anatomofisiológicas do paradigma experimental. Corrobora-se, assim, a ideia lacaniana ressaltada por Elia (2007) de que, apesar de a categoria de sujeito ser uma invenção da ciência moderna, ela não o toma em consideração, não operando com ele, nem sobre ele. Ao contrário, ainda que suponha a existência do sujeito, a ciência moderna o exclui de seu campo operatório. De fato, esse é um tema absolutamente contemporâneo, uma vez que se tem, hoje, a maior valorização do dado do que a do sujeito na produção de ciência. A pesquisa que leva em consideração um problema cuja aproximação e investigação subordinam-se à quantificação, à mensuração e

1 Endereço para correspondência: Campus Central, Pontíficia Universidade Católica do Rio Grande do Sul, Avenida Ipiranga, 6681, Partenon, Porto Alegre, RS, Brasil. CEP: 90619-900. E-mail: carolfalcao@yahoo.com aos parâmetros de replicabilidade acaba priorizada, no âmbito científico, em detrimento de modalidades investigativas que têm a complexidade do sujeito e dos fenômenos humanos como foco de estudo. Assim, a denominação de científico acaba restrita, ainda, ao paradigma experimental. Ademais, Rojas Hernández, Reyes Arellano e Méndez Martinez (2011) salientam que a ciência positiva contemporânea e a pesquisa dela decorrente operam um dualismo que executa uma separação entre o sujeito investigador e o objeto investigado. A consequência é, conforme Jardim e Rojas Hernández (2010), uma estrutura binária que delega à ciência o papel de explicar o conhecimento sobre o objeto através de métodos que pretendem ser independentes do sujeito. Exclui-se, consequentemente, a possibilidade de reconhecer que na relação entre o sujeito e o objeto se produz conhecimento.

A investigação científica no contexto universitário está prioritariamente sustentada desde os parâmetros do racionalismo contemporâneo, e as metodologias empregadas nas pesquisas seguem primordialmente os ditames do pensamento popperiano, o qual averigua a possibilidade de falseamento da hipótese tida como correta e verdadeira (Jardim \& Rojas Hernandez, 2010; Rojas Hernández et al., 2011). A pesquisa psicanalítica oferece, contudo, uma importante e legítima alternativa ao modelo de fazer ciência sob a égide do positivismo. Parte-se, neste artigo, da proposta de Minerbo (2000) de consideração da psicanálise como matriz de estratégias de investigação para propor uma estratégia de pesquisa com o método psicanalítico. Toma-se a ideia de estratégia proposta pela autora para, muito mais 
do que questionar todos os significantes que estão imbuídos na definição de método e que remetem à estrita visão de ciência, evidenciar o trabalho criativo que a pesquisa psicanalítica demanda. O maior desafio da criação de uma estratégia de pesquisa com o método psicanalítico refere-se à essencial manutenção da especificidade e do rigor que lhes são próprios.

\section{A investigação em psicanálise: elementos constituintes}

Acredita-se ser a atividade clínica o ponto de partida para os genuínos questionamentos que promovem o devir em psicanálise. Todavia, pensa-se que as problematizações decorrentes do olhar investigativo sobre os padecimentos humanos podem e devem ser conduzidas para além do campo clínico. Como especifica Rosa (2004), o método em psicanálise é a "escuta e interpretação do sujeito do desejo, em que o saber está no sujeito, um saber que ele não sabe que tem e que se produz na relação que será chamada transferencial" (p.341). Dessa forma, sustenta-se que o trabalho com o método psicanalítico está pautado na consideração do sujeito em sua singularidade e como portador de um saber inconsciente. Logo, como não é apenas na clínica psicanalítica que este sujeito se faz presente, não deve ser somente no âmbito técnico a intervenção sobre os questionamentos que a existência humana convoca.

A pesquisa com o método psicanalítico atribui valor à produção de conhecimento oriundo da escuta singular da subjetividade, sendo imprescindível o conhecimento construído não a fim de generalizações, mas, sim, no sentido do aprofundamento e da problematização da questão ou problema de pesquisa. Logo, a especificidade do método psicanalítico sustenta-se na possibilidade de interpretação do que é desvelado do fenômeno que se estuda. Para Figueiredo e Minerbo (2006), a interpretação é sempre relativa ao processo que a produziu, na medida em que esse processo é singular e, portanto, irrepetível. A verdade de uma interpretação será relativa, podendo existir outra interpretação igualmente verdadeira ou até mesmo mais útil e, ainda assim, sem desfazer a primeira ou retirar seu valor. Por isso, uma interpretação é provisória e parcial, uma vez que advém de uma perspectiva selecionada do seu objeto (Figueiredo \& Minerbo, 2006). Conforme Batista e Cunha (2012), uma interpretação psicanalítica nunca é arbitrária, pelo fato de não apenas se inscrever em uma experiência transferencial, garantida pela abstinência do psicanalista e por sua atenção flutuante, mas também de somente ocorrer respeitando o livre associar do sujeito. Já Coelho e Santos (2012) compreendem que a interpretação é o maior limite e a maior potência do método psicanalítico. Os autores resgatam o conceito de "arbitrariedade da função do intérprete", formulado por Birman (1994) para marcar que a interpretação é justamente o elemento da pesquisa psicanalítica que a situa definitivamente fora do campo do empirismo, deslocando o saber psicanalítico "do campo do determinismo para o campo do indeterminismo" (p.20).

Pode-se retomar o texto freudiano "Construções em Análise" para ampliar ainda mais a discussão acerca da investigação e construção do conhecimento em psicanálise.
Freud (1937/1996) refuta a crítica de que a regra em uma análise é "cara você ganha, coroa você perde", isto é, que o psicanalista está sempre certo em sua interpretação. Ao contrário, segundo Green (2008), são as vicissitudes provocadas pela interpretação o que evidencia sua fertilidade ou esterilidade. No caso da pesquisa em psicanálise, podese pensar que as interpretações produzidas jamais terão o objetivo de responder permanentemente e/ou circunscrever o fenômeno estudado; na verdade, terão por objetivo ampliar o olhar e promover uma abertura para novas compreensões do fenômeno. Trata-se de interpretar o que se oferece à possibilidade de conhecimento e não de esgotá-lo ou de enunciar dogmas.

Considerando as peculiaridades da pesquisa psicanalítica, Lo Bianco (2003) também destaca o quanto o pesquisador está implicado no material que analisa, visto ser esse oriundo de um processo viabilizado pela transferência. Por isso, a neutralidade na investigação é impossível e, inclusive, indesejada, devendo-se manter a necessária distinção entre neutralidade e abstinência. Ao afirmar que um tratamento psicanalítico é conduzido em estado de abstinência, Freud (1937/1996) dá luz a uma condição que também se faz sine qua non na pesquisa psicanalítica. Considerar que o psicanalista-pesquisador deve manter-se abstinente diz respeito ao não exercício da sugestão e ao respeito ao desejo e à associação livre do sujeito. Destaca-se que a pesquisa psicanalítica parte de um problema de pesquisa, mas não pode manter-se restrito a ele, devendo o pesquisador ser capaz de deixar-se surpreender pelo que lhe aparece no transcorrer do estudo. As surpresas, contudo, só existirão se a abstinência for mantida e a singularidade do fenômeno investigado aparecer.

A coragem da psicanálise em mostrar ser a neutralidade um ideal científico moderno inatingível provoca rechaços na academia, quando inadvertidamente toma-se essa constatação como sinônimo de ausência de cuidados éticos e de rigor metodológico. Ressalta Loureiro (2002) que o método psicanalítico possui uma passividade que lhe é intrínseca, uma vez que ao objeto de estudo deve-se deixar seguir seu próprio percurso. Tal característica, porém, não implica falta de atividade do pesquisador: esse, com sua atenção flutuante, guia-se pelas associações do(s) sujeito(s), procedendo, assim, àconstrução das etapas do estudo. Afirma-se, portanto, o necessário processo de criação que é inerente à pesquisa com o método psicanalítico,o que não significa, de forma alguma, a perda do rigor científico, mas, a construção de vias de acesso ao fenômeno a investigar. Baseada nessas afirmações, apresenta-se uma proposta de estratégia de investigação com o método psicanalítico.

\section{Há pesquisa psicanalítica para além da clínica psicanalítica?}

Encontra-se na literatura psicanalítica uma série de discussões acerca da viabilidade e das características necessárias à condução da pesquisa psicanalítica (Batista \& Cunha, 2012; Coelho \& Santos, 2012; Cunha, 2007; Dunker, 2011; Figueiredo \& Minerbo, 2006; Iribarry, 2003; Jardim \& Rojas Hernández, 2010; Lo Bianco, 2003; Rojas Hernández et al., 2011; Rosa, 2004; Sampaio, 2006; Sauret, 
2003). É possível perceber, entre os autores, uma linha de compreensão que propõe ser a clínica o espaço a partir do qual a pesquisa psicanalítica pode ocorrer - proposição de que método e técnica coincidem - e uma outra linha de compreensão que considera a possibilidade de condução de uma pesquisa genuinamente psicanalítica em outros campos além da clínica.

Dentre as afirmativas desse primeiro grupo de autores, destaca-se a consideração de Lo Bianco (2003) sobre ter o objeto psicanalítico a característica de se deixar circunscrever apenas em análise, o que faz com que a pesquisa psicanalítica tenha na clínica seu apoio fundamental. Conforme a autora, "é na referência ao material clínico que a pesquisa ganha seu colorido, sua vivacidade e, acima de tudo, sua originalidade em relação às pesquisas desenvolvidas em outros campos" (Lo Bianco, 2003, p. 120).

Apesar de não ser objetivo deste artigo problematizar essa divergência, depreende-se que ela é um importante sinal de que as considerações sobre pesquisa psicanalítica não são unívocas; portanto, esse é um tema em aberto, o qual, necessariamente, deve seguir sendo problematizado. A opção neste artigo se dá na direção de sustentar possibilidade de pesquisa psicanalítica extra-clínica. A principal linha de argumentação quanto à possibilidade de realização de pesquisas com o método psicanalítico para além da clínica diz respeito não apenas à universalidade do inconsciente e de seus modos de expressão, bem como ao fato de que fenômenos como a transferência e a associação livre não têm sua ocorrência restrita à situação de análise. Nesse sentido, a pesquisadora francesa Marie-Jean Sauret (2003) acredita que não é possível existir pesquisa clínica sem a mobilização da palavra, ou seja, "todo ato de palavra que mobiliza um encontro entre um sujeito e um outro (...) é suscetivel de uma avaliação com os elementos da estrutura" (p.97). Por isso, a autora propõe uma diferenciação, baseada nos pressupostos lacanianos, entre a Psicanálise - o tratamento que se passa no dispositivo analítico - e o método Psicanalítico. O último diz respeito à decifração dos significantes, levando em consideração os aspectos inconscientes que intervêm em sua organização. Ainda de acordo com Sauret (2003), "o método mantém a ética da psicanálise enquanto ela preservar essa falta como causa do desejo... e enquanto ela der a prova de sua articulação com o discurso analítico" (p.98). Assim, para a autora, o método psicanalítico é, em última instância, "constituído daquilo que, pela experiência da análise, é transponivel fora dela, sem romper o laço com o discurso psicanalítico" (p.98), a saber, a existência do inconsciente, a concepção de sujeito, a escuta, a transferência e a intervenção psicanalítica. Sauret (2003) propõe a diferenciação entre a pesquisa psicanalítica - aquela que é conduzida necessariamente por um psicanalista - e a pesquisa que se apoia na psicanálise, sendo orientada por ela.

Diferenciação semelhante é proposta por Figueiredo e Minerbo (2006). Para os autores, é preciso distinguir a "pesquisa em psicanálise", a qual se refere a um conjunto de incursões investigativas que mantêm relações com a psicanálise, da "pesquisa com o método psicanalítico", na qual há a exigência de um psicanalista em sua capacidade de escuta. Para os autores, uma pesquisa com o método psicanalítico é sempre capaz de trazer novas contribuições à psicanálise. Não há, contudo, conforme Figueiredo e Minerbo (2006), o confinamento das pesquisas com o método psicanalítico ao dispositivo analítico. Esses estudos podem tratar de fenômenos socioculturais, fenômenos psíquicos abarcados fora da situação psicanalítica em sentido estrito, por exemplo, uma vez que a dimensão clínica é mais ampla do que a situação da análise, visto que produz efeitos de escuta e efeitos terapêuticos.

Nesse sentido, Dunker (2011) pondera que não se deve confundir método de investigação psicanalítico com o método de tratamento psicanalítico, pela heterogeneidade e característica do primeiro. Isto é, há, no método de investigação, uma heterogeneidade de fontes, uma diversidade de meios e uma distinção de princípios, que o constitui como uma estrutura aberta, comunicando-se livremente com outros discursos e estratégias de investigação, já o método de tratamento tem uma estrutura fechada tal como a metáfora freudiana do jogo de xadrez. Pode-se estabelecer, então, para esse autor, que o método de investigação fundamenta o método de tratamento. Ressalta o autor que "a ligação entre método de tratamento e método de investigação não é, contudo, de subserviência ou prioridade, mas de mútua utilidade prática e teórica" (Dunker, 2011, p. 322).

Segundo Rosa (2004), a principal crítica recebida na aplicação do método psicanalítico a um material que não provém da clínica diz respeito à legitimidade da interpretação dele decorrente. Como explica a autora, há o questionamento acerca do possível caráter selvagem dessa interpretação, visto que é produzida fora do setting. Quanto à questão da selvageria, Batista e Cunha (2012) afirmam que a prevenção a qualquer produção de uma interpretação selvagem apoiase no fato de ela ser conduzida por um psicanalista e produzida numa situação de escuta e de transferência. Os autores retomam o texto de Freud (1910/1996) de que uma interpretação selvagem é aquela produzida exclusivamente pelo saber prévio do psicanalista sem levar em consideração a associação livre do sujeito. Logo, a temática de investigação com o método psicanalítico pode ou não ter como nascedouro a experiência clínica do psicanalista-pesquisador; porém não pode prescindir da recusa a um saber prévio ao processo de investigação. A fim de problematizar tal questão, Cunha (2007) destaca o quanto existe uma tendência na pesquisa psicanalítica de se considerar que a caracterização estrita do setting garante a experiência clínica e, portanto, a execução de uma pesquisa com o método psicanalítico. Para o autor, contudo, não é o setting que sustenta a clínica, e sim a transferência, sendo ela a garantia da legitimidade da produção de conhecimento em psicanálise. Nesse sentido, Batista e Cunha (2012) enfatizam que o invariável no método psicanalítico refere-se ao aparecimento da relação transferencial, desde a qual os conteúdos inconscientes se fazem presentes. As técnicas de acesso ao sujeito e à exploração do problema de pesquisa são sempre variáveis, sendo variáveis, inclusive, no campo da análise.

No que diz respeito à transferência, Rosa (2004) discute o quanto o método psicanalítico parte do fenômeno em direção ao conceito, construindo uma metapsicologia que não é isolada, mas, sim, fruto da escuta. Essa está sustentada pela transferência, a qual se apresenta, segundo a autora, como um instrumento e um método não restrito à situação 
analítica, pois o sujeito de inconsciente está presente em todo enunciado discursivo. Para Rosa (2004), isso significa afirmar a possibilidade de trabalho com a escuta psicanalítica de entrevistas ou depoimentos, por exemplo, "colhidos em função do tema do pesquisador que, por sua vez, reconstrói sua questão nessa relação" (p.342). Batista e Cunha (2012) igualmente sustentam o caráter universal da transferência, fenômeno não produzido pela análise. Para os autores, é justamente a instauração de uma experiência transferencial que garante o rigor do método psicanalítico, na medida em que a genuína interpretação será construída na experiência intersubjetiva da transferência. Na mesma perspectiva, Coelho e Santos (2012) afirmam ser necessário admitir a possibilidade da aplicação do método psicanalítico a outras situações que não estritamente a clínica, incluindo, ainda, outras modalidades de coleta de dados, além das entrevistas e dos depoimentos. Para os autores, a leituraescuta exemplificada por Iribarry (2003) demonstra como uma leitura pode ser escutada a partir da atenção flutuante e do trabalho com as transcrições de entrevistas (campo transferencial do pesquisador com o material analisado).

Nesse sentido, considerar a psicanálise uma ferramenta válida como método de investigação dos fenômenos humanos, mesmo não sendo eles oriundos da clínica, não significa fazer uma psicanálise aplicada, uma psicanálise menos pura, ou até mesmo uma psicanálise selvagem. Ao contrário, diz respeito, sim, a criar formas de efetivamente problematizar e intervir nas expressões humanas através de diferentes estratégias, quer sejam elas técnicas, quer sejam elas metodológicas. Ambas fundamentam-se na vigência de uma disciplina que, em seu vigor, pode ser definida como psicanálise ampliada.

\section{Estratégia clínico-interpretativa: uma proposta de investigação extra-clínica}

A apresentação de um delineamento de estratégia de pesquisa construído a partir do método psicanalítico encontra apoio nas ideias de Figueiredo e Minerbo (2006) sobre ser a pesquisa com o método psicanalítico "uma atividade em que se constituem e se transformam 'objetos', 'pesquisadores' e 'meios' ou 'instrumentos' de investigação" (p.262). Dessa forma, entende-se ser válido, como sustentam os autores, atribuir à pesquisa psicanalítica a efetiva possibilidade de que o sujeito de pesquisa, o objeto de pesquisa e os meios de investigação sejam descobertos e inventados simultaneamente. É possível criar novos meios de investigação em psicanálise, desde que se mantenha o que de rigoroso há no método: as dimensões de abstinência, escuta, transferência e interpretação.

A proposta a ser apresentada baseia-se, também, na validade da pesquisa psicanalítica extra-clínica e utiliza, ainda, o valor do caso clínico tal como apresentado por Nasio (2001). Para o autor, um caso clínico é o relato de uma experiência singular, escrita pelo psicanalista, para atestar seu encontro com um sujeito e que "exprime a própria singularidade do ser que sofre e da fala que ele nos dirige" (p.11). Conforme Nasio (2001), um caso clínico contém três funções: didática, metafórica e heurística. A primeira diz respeito à possibilidade de o exemplo clínico evidenciar conceitos metapsicológicos e, assim, transmitir a psicanálise. Já a segunda função refere-se ao fato de uma ilustração clínica ser capaz de se relacionar tão intimamente com os conceitos psicanalíticos que a ilustração passa a ser uma metáfora do conceito. Por fim, a função heurística aponta o quanto um caso clínico pode ser gerador de conceitos, isto é, "a fecundidade demonstrativa de um exemplo clínico é tão frutifera que vemos proliferarem novas hipóteses que enriquecem e adensam a trama da teoria" (Nasio, 2001, p. 17). O ponto fundamental salientado na proposta de uma estratégia de investigação nesse artigo é o fato de Nasio (2001) colocar lado a lado Casos Clínicos que se originaram de experiências da clínica psicanalítica com outros que se originaram do encontro do psicanalista com o sujeito (ou mais especificamente com sua história) em situações que não foram de tratamento. Apontam-se, por exemplo, o caso de Schreber trabalhado por Freud e o caso das irmãs Papin, trabalhado por Lacan. Logo, seguindo o percurso desses psicanalistas, pode-se encontrar brechas para problematizar a relevância do "dado" de pesquisa oriundo de um campo que não seja o espaço de análise. De fato, depreende-se dos trabalhos de Freud sobre Schreber e Hans que o valor do caso clínico não está em sua origem na clínica psicanalítica, mas, sim, no trabalho de escuta que provoca no psicanalista. Os efeitos dessa escuta são transformadores porque atuam no devir da psicanálise, tanto no âmbito teórico, como no âmbito técnico.

$\mathrm{Na}$ academia é fundamental que se possa exercitar o labor criativo de um psicanalista de tal forma a não restringir ou circunscrever o valor do que produz de conhecimento em psicanálise unicamente ao âmbito clínico. Nesse intuito, é possível basear-se na diferenciação entre estratégia e programa proposta por Hornstein (2013). Conforme ressalta o autor, uma estratégia sempre supõe a modificação das ações já estruturadas diante do surgimento de um novo elemento que altera a configuração existente. Ao contrário de um programa - que pressupõe passos rigidamente estruturados - a estratégia respeita a abertura aos improvisos e à consideração constante da dúvida. Logo, a estratégia é oposta a uma atitude dogmática, uma vez que essa última pressupõe uma verdade que se torna inquestionável. Ao alinhar-se ao modelo de pensamento complexo, próprio da ciência contemporânea, o método psicanalítico deve, para Hornstein (2013), incluir invenções, arte, iniciativas e criação de estratégias, mantendo-se distante dos programas e das receitas, de forma a efetivamente relacionar-se com a capacidade do psicanalista de interrogar-se.

Denomina-se estratégia clínico-interpretativa, a estratégia de pesquisa apresentada, cujos passos que compõem sua estruturação estão encadeados de forma a sistematizar elementos essenciais a um processo de investigação. $\mathrm{O}$ espaço reservado ao imprevisto no decorrer da investigação está salvaguardado na flexibilidade e na criatividade passíveis à excecução da estratégia, que permitem as aproximações singulares ao fenômeno que se busca estudar.

$\mathrm{Na}$ linha de raciocínio a seguir, a fim de apresentar as etapas da estratégia clínico-interpretativa, opta-se por tomar como exemplo um conjunto de entrevistas como o recurso que acompanhará o desenvolvimento da apresentação das 
etapas dessa estratégia. Tem-se, portanto, um fenômeno a ser investigado, traduzido pelo pesquisador na modalidade de seu tema ou problema de pesquisa. Caso a entrevista seja a ferramenta a ser utilizada no acesso à fala (dados do fenômeno), é possível a alternativa de realização de um conjunto de entrevistas ou de quantas forem consideradas adequadas à efetiva aproximação e investigação do tema de pesquisa. Vale ressaltar que se considera um conjunto de entrevistas mais pertinente ao fomento e ao estabelecimento de uma relação transferencial que permita o acesso ao mundo psíquico de quem conta acerca de si mesmo. Todavia, também o número de entrevistas pode variar, em função das efetivas condições de acesso ao sujeito. Por exemplo, durante a condução da pesquisa "O sujeito da dependência química: uma proposta de intervenção psicanalítica" (Macedo, 2012), foi proposta uma série com cinco entrevistas, sendo uma delas com algum familiar próximo ao sujeito drogadito. Durante a condução do estudo, contudo, percebeu-se a impossibilidade de efetivamente concluir a série de entrevistas, por motivos diversos (fugas do sujeito da instituição de tratamento, indisponibilidade dos familiares, etc.), concluindo-se ser não apenas próprio da problemática que estava sendo investigada, bem como um elemento encadeado nas histórias de vida que levavam o sujeito ao encontro do objeto droga. Assim, é possível que, ao longo da condução do estudo, a proposta inicial tenha que ser revista e readaptada a fim de que o pesquisador e o sujeito participante consigam executá-la. De toda forma, um conjunto de entrevistas composto de três a cinco encontros oferece ao psicanalista-pesquisador a possibilidade de fomentar ao sujeito da pesquisa um vínculo de confiança, de tal forma a estabelecer uma dupla de trabalho e um espaço de escuta, no qual o sujeito possa falar de si, de sua história e de seus conflitos e de suas fantasias. Por trata-se de uma estratégia de investigação psicanalítica, a presença de um psicanalista pesquisador, ou seja, um psicanalista na operacionalização do método é condição sine qua non do processo. Considera-se que um psicanalista pode oferecer uma condição de escuta ao sujeito participante ou a qualquer outro material de pesquisa, garantindo, para isso, a abstinência e a atenção flutuante necessárias ao processo do livre associar. Uma vez realizadas as entrevistas, elas podem ser transcritas. As transcrições são válidas, inclusive, como documentos da pesquisa e, portanto, de valor inegável. Opta-se, contudo, pelo trabalho prioritário com as entrevistas em áudio, pois se acredita que elas permitem um efetivo exercício de escuta da dupla por parte do psicanalistapesquisador. Isso também permite afirmar que o trabalho de análise do material, na estratégia clínico-interpretativa, exige a experiência clínica do psicanalista-pesquisador. Justamente essa posição de escuta, tomada pelo psicanalista-pesquisador ao longo do trabalho com o áudio das entrevistas, faz propor que o material a ser analisado não precisa, necessariamente, ser oriundo de entrevistas feitas apenas pelo próprio pesquisador. Considera-se que a escuta produzida por uma outra dupla (outro entrevistador e o sujeito entrevistado) pode ser muito rica para trabalhar os aspectos transferenciais e contratransferenciais ocorridos, à luz do que é um espaço de supervisão. Propõe-se que o material transcrito seja utilizado

1 Projeto Fomentado pelo CNPq. Edital CNPq 02-2010 como material de apoio à escuta, no qual o pesquisador possa fazer marcações de trechos de fala do sujeito, por exemplo. Contudo, além desse material, considera-se fundamental a feitura de anotações sobre o caso, tanto no que diz respeito a dados mais descritivos, a marcadores da história, como quanto às hipóteses interpretativas (na medida em que elas surjam tanto na escuta do áudio, quanto na leitura do material transcrito), dos pontos que chamam a atenção na escuta e dos marcadores transferenciais e contratransferenciais que forem se fazendo presentes. Essas anotações visam não somente à apropriação do caso por parte do psicanalistapesquisador, bem como ao estabelecimento de questões e hipóteses interpretativas provenientes de seu exercício de escuta dos dados.

Ao final da escuta de cada caso, constrói-se uma narrativa do sujeito: uma narrativa clínica. Esta deve abarcar os marcadores de história material (dados descritivos, por exemplo, referente à realidade material), história vivencial (como o sujeito viveu e significou o vivido, referente à realidade psíquica), indicadores transferenciais e contratransferenciais e, também, as hipóteses interpretativas construídas pelo pesquisador.

É resultante do processo de construção de narrativa um primeiro trabalho de interpretação acerca do que foi escutado. Retomam-se aqui as contribuições de Figueiredo e Minerbo (2006), pois na análise do material interpreta-se, "seguindo os mesmos procedimentos usados na clínica psicanalítica: uma escuta flutuante, isto é, descentrada do tema central, intencionado; um recorte do texto privilegiando temas, expressões, brechas, palavras ou quaisquer elementos que sirvam como cunha para desconstruir o texto" (p.263). É possível, então, construir novos sentidos e produzir novas verdades sobre a fala do sujeito. É fundamental o uso da contratransferência como ferramenta de escuta, considerando os efeitos que a entrevista, o discurso do sujeito e o trabalho da dupla causam no intérprete.

Segue-se ao primeiro momento de escuta e interpretação - construção de narrativa - um segundo momento de análise, o qual se considera tão relevante quanto um espaço de supervisão para a atividade clínica do psicanalista. Esse segundo momento toma como inspiração a efetiva dinâmica da supervisão na medida em que se propõe uma ampliação/ reflexão de elementos presentes no material. Trata-se de um momento de escuta da escuta, quando psicanalista-orientador e psicanalista-pesquisador debruçam-se juntos sobre os casos, a partir da narrativa clínica construída no primeiro momento da análise do material. Como destacam Macedo e Dockhorn (2009), na singularidade da relação estabelecida pela dupla supervisor-supervisionando, constrói-se um espaço de discussão que tem como ponto de partida o material clínico. Afinal, no exercício de supervisão, o supervisor exerce a capacidade de utilizar sua própria experiência clínica como recurso de escuta sobre o caso. Além dos benefícios dessa etapa da escuta da escuta sobre as problematizações possíveis acerca de cada caso clínico, considera-se que esse segundo momento de análise é fundamental por permitir uma triangulação dos dados. A triangulação permite nova problematização dos elementos de escuta que serviram para a construção das hipóteses interpretativas. No encontro da escuta do psicanalista-orientador com o escutar do 
psicanalista-pesquisador produz-se a ampliação do processo final de interpretação dos dados. É importante a ressalva de que a estratégia clínico-interpretativa não limita sua aplicabilidade à situação de pesquisa na academia e tampouco à relação orientador-orientando (mestrando ou doutorando). Preserva-se o objetivo dessa etapa do método na possibilidade de interlocução clínica entre dois ou mais psicanalistas, ou seja, a etapa escuta da escuta, independe da meta acadêmica de uma pesquisa.

Considerando, ainda, as críticas recorrentes ao método psicanalítico acerca da arbitrariedade das interpretações resultantes numa pesquisa, acredita-se ser esse processo de triangulação dos dados fundamental para a estratégia clínico-interpretativa de pesquisa. Isso ocorre não por uma atribuição de não-veracidade às interpretações feitas no primeiro momento (pelo psicanalista-pesquisador), mas, sim, por acreditar-se que a discussão clínica sempre permite a complexização sobre a compreensão de um sujeito e suas problemáticas psíquicas. Além disso, esse espaço de escuta da escuta permite que sejam compreendidos pela dupla (supervisor X supervisionando/psicanalista-orientador $\mathrm{X}$ psicanalista-pesquisador-interlocutor), os efeitos contratransferenciais despertados na escuta, de tal forma que eles possam ser efetivas ferramentas de interpretação do material clínico. São, dessa forma, resultantes desse segundo momento, hipóteses interpretativas acerca de cada caso clínico trabalhado (em um nível individual) e, também, eixos interpretativos em relação ao conjunto de casos utilizados em todo estudo. Se a pesquisa for levada a cabo com um único caso clínico, essas duas dimensões interpretativas coincidirão; porém, se forem utilizados mais casos, serão construídas interpretações individuais de cada sujeito e, posteriormente, os eixos interpretativos que correspondem à aproximação com a temática estudada. A partir da experiência de elaboração da estratégia clínico-interpretativa, utilizaramse na construção dos eixos interpretativos critérios que emergiram de exaustivas leituras, da escuta e da discussão dos materiais que compuseram o estudo que deu origem a essa estratégia investigativa. Cabe ressaltar que, na atenção necessária à especificidade e ao rigor próprios à psicanálise, não se trata de critérios que devam ser "aplicados" a novas investigações. Assim como os eixos interpretativos construídos, tampouco os critérios são predeterminados ou, até mesmo, capazes de esgotar a necessária criatividade exigida do psicanalista-pesquisador diante dos dados produzidos na singularidade de seu estudo. Portanto, os eixos interpretativos construídos no referido estudo diziam respeito a elementos que se repetiram ao longo das narrativas (critério de repetição), que se sobressaíram pela sua intensidade (critério de intensidade), que se conectaram retroativamente ao problema de pesquisa e aos objetivos do estudo (critério de pertinência) e que levaram à complexização de elementos da metapsicologia, auxiliando na compreensão da problemática (critério metapsicológico). Ressalta-se, porém, que esse retorno ao problema de pesquisa não deve estar relacionado a uma condução sugestiva das interpretações, mas sim, ao necessário retorno ao tema da pesquisa para que se possa efetivar uma discussão teórico-clínica dos achados no terceiro momento do método. Portanto, caberá à etapa de discussão teórico-interpretativa a sustentação teórica dos eixos interpretativos construídos nas primeiras duas etapas, através da articulação com a metapsicologia psicanalítica.

Destaca-se, assim, que, ao fazer trabalhar a metapsicologia, cada eixo interpretativo promove um movimento teóricoclínico capaz de aprofundar a compreensão do fenômeno estudado, promovendo um potencial movimento no devir da produção de conhecimento em psicanálise. Os eixos interpretativos têm o propósito de promover o acesso àquilo que foi compreendido do fenômeno. Contribuem, simultaneamente, para explicitar a singularidade do fenômeno que se objetivou investigar e para produzir conhecimento em psicanálise. Alinha-se, assim, a proposição da estratégia clínico-interpretativa à ética da psicanálise, na medida em que se considera que a produção do conhecimento só ocorrerá mediante o acesso aos fenômenos inconscientes e seus efeitos. Corrobora-se a afirmativa de Sauret (2003) sobre ser o alinhamento à ética da psicanálise garantido pelo método que se sustenta na existência da falta, própria ao desejo, impulsionadora das ações humanas.

Afirma-se, a partir dos passos constituintes da estratégia clínico-interpretativa, ser no encontro entre a abertura do fenômeno e a proposição de um conhecimento não dogmático que reside a força de uma delineamento metodológico que se propõe a interpretar elementos de um fenômeno, sem a intenção de esgotá-lo. A estratégia clínico-interpretativa permite um exercício criativo de investigação, ao mesmo tempo em que possibilita sua sistematização.

\section{Considerações Finais}

No percurso de construção da estratégia clínicointerpretativa, partiu-se de uma complexa, mas necessária, discussão acerca da validade da pesquisa com o método psicanalítico para além dos fatos e contextos clínicos. Desse modo, apoiando-se no entendimento de que a escuta é um processo sustentado pelo psicanalista e não pelo setting, acredita-se que não só a abstinência do psicanalistapesquisador com o material a ser estudado, bem como a inevitável transferência que se instala com esse material tornam possível a utilização frutífera do método psicanalítico em pesquisas cujos dados não são oriundos da clínica.

$\mathrm{O}$ encontro da psicanálise com a universidade, apesar de duradouro, tem sido cada vez mais desafiador. Além de duramente criticada, cada vez mais se percebe o encolhimento dos espaços psicanalíticos nas esferas universitárias, quer seja em número de créditos nos currículos dos cursos de graduação, quer seja nas diferentes esferas dos programas de pós-graduação em nível nacional. Ainda que existam pesquisas psicanalíticas que se utilizam de fatos clínicos e têm seu trâmite aprovado pelos comitês de ética em pesquisa de universidades brasileiras, o uso de material clínico em pesquisas suscita, ainda, muitos desafios na academia. Além disso, sabe-se que, em outras situações, a clínica pode despertar questionamentos importantes, porém os materiais clínicos não podem ser utilizados pela impossibilidade de garantia de sigilo. Enfim, existem situações com as quais o psicanalista se confronta em seu encontro com a academia que impedem a utilização de sua clínica, ainda que esta seja a mola propulsora para seu desejo de investigar. Nesse contexto, 
considera-se que, diante das reais dificuldades de trabalho acadêmico em relação ao material oriundo do exercício clínico da psicanálise, parece ter o psicanalista-pesquisador duas alternativas: permanecer numa posição defensiva diante da afirmação da impossibilidade de essa modalidade de pesquisa fazer-se presente no cenário universitário, rebatendo as críticas com o velho argumento da resistência provocada pela psicanálise, ou imbuir-se de um trabalho criativo que atenda à especificidade $\mathrm{e}$ ao rigor próprios à psicanálise no intuito de demarcar sua legítima inserção - mesmo que diferenciada - no cenário da universidade. Assim, a proposição da estratégia clínico-interpretativa decorre da crença de ser necessário recorrer a recursos criativos de investigação, reconhecendo os impedimentos e, também, o não desejo de formatar a psicanálise no modelo científico próprio do empirismo. Acredita-se que, ao propor uma estratégia de investigação, não se renuncia à essência de um método que tem na interrogação diante do desconhecido sua força fundamental. A estratégia clínico-interpretativa sustenta sua coerência com os pressupostos da psicanálise ao delegar ao psicanalista-pesquisador a interpretação do fenômeno, deixando em aberto o nascedouro da interrogação. Dessa forma, a estratégia proposta neste artigo possibilita a investigação de qualquer fenômeno humano que se constitua como um interrogante à capacidade criativa de escuta e de interpretação de um psicanalista.

Dessa forma, a primeira etapa da estratégia denominada construção de narrativa permite a construção da narrativa clínica. Nos elementos sistematizados a partir dessas narrativas, tem-se a segunda etapa da estratégia, ou seja, a escuta da escuta, na qual a entrada de um terceiro (psicanalista-orientador) permite a triangulação de dados e, assim, a construção de eixos interpretativos do material de pesquisa. Chega-se, portanto, ao terceiro e último momento da estratégia. Na etapa da discussão teórico-interpretativa, consolida-se o objetivo fundamental da estratégia de investigação, a saber, o recurso à psicanálise na modalidade de pesquisa que permite interpretações e ampliações de significados ao fenômeno estudado. Logo, com a proposição da estratégia clínico-interpretativa, objetivou-se ampliar as ferramentas de pesquisa em psicanálise, além de fomentar ainda mais a inserção de psicanalistas na pesquisa acadêmica. Afinal, na universidade, a psicanálise mantém-se viva e não reduzida às, muitas vezes autofágicas, instituições psicanalíticas.

\section{Referências}

Batista, K. R. O., \& Cunha, E. L. (2012). A experiência psicanalítica na investigação social: considerações sobre método. Ecos, 2(2), 260-275.

Birman, J. (1994). Psicanálise, ciência e cultura. Rio de Janeiro: Jorge Zahar.

Coelho, D. M., \& Santos, M. V. O. (2012). Apontamentos sobre o método na pesquisa psicanalítica. Analytica, 1(1), 90-105.
Cunha, E. L. (2007, maio). A psicanálise como método de investigação da cultura: uma interrogação sobre os limites da clínica. III ENECULT: Encontro de Estudos Multidisciplinares em Cultura, Salvador, Brasil.

Dunker, C. I. L. (2011). Estrutura e Constituição da Clínica Psicanalítica. São Paulo: Annablume.

Elia, L. (2007). O conceito de sujeito. Rio de Janeiro: Zahar.

Figueiredo, L. C., \& Minerbo, M. (2006). Pesquisa em Psicanálise: algumas ideias e um exemplo. Jornal de Psicanálise, 39(70), 257-278.

Freud, S. (1996). Psicanálise Silvestre.In J. Strachey (Ed. \& Trad.), Edição Standard Brasileira das Obras Psicológicas Completas de Sigmund Freud (Vol. 11, pp. 231-239). Rio de Janeiro: Imago. (Obra originalmente publicada em 1910)

Freud, S. (1996). Construções em análise. In J. Strachey (Ed. \& Trad.), Edição Standard das Obras Psicológicas Completas de Sigmund Freud (Vol. 23, pp. 235-287). Rio de Janeiro: Imago. (Trabalho original publicado em 1937)

Green, A. (2008). De loucuras privadas. Buenos Aires: Amorrortu.

Hornstein, L. (2013). Las encrucijadas actuales del psicoanálisis: subjetividad y vida cotidiana. Buenos Aires: Fondo de Cultura Económica.

Iribarry, I. N. (2003). O que é pesquisa psicanalítica? Ágora, 6(1), 115-138.

Jardim, L. L. \& Rojas Hernández, M. C. (2010). Investigación psicoanalítica en la universidad. Estudos de Psicologia (Campinas), 27(4), 529-536.

Lo Bianco, A. C. (2003). Sobre as bases dos procedimentos investigativos em psicanálise. Psico-USF, 8(2), 115-124.

Loureiro, I. R. B. (2002). Sobre algumas disposições metapsicológicas de inspiração freudiana. In E. I. Queiroz \& A. R. Silva (Eds.), Pesquisa em psicopatologia fundamental (pp. 143-156). São Paulo: Escuta.

Macedo, M. (2012). O sujeito da dependência química. Projeto de Pesquisa. Edital CNPQ 02/2010.

Macedo, M. M. K., \& Dockhorn, C. N. B. F. (2009). A supervisão em psicanálise: o fazer na clínica. In M. M. K. Macedo (Eds.), Fazer Psicologia: uma experiência em clínica-escola (pp. 207-219). São Paulo: Casa do Psicólogo.

Minerbo, M. (2000). Estratégias de investigação em psicanálise. São Paulo: Casa do Psicólogo.

Nasio, J-D. (2001). Os grandes casos de psicose. Rio de Janeiro: Zahar.

Rojas Hernández, M. C., Reyes Arellano, M. A., \& Méndez Martinez, S. L. (2011). Posibilidades del trabajo investigativo psicoanalítico en la universidad. Uaricha Revista de Psicología, 15, 1-12.

Rosa, M. D. (2004). A pesquisa psicanalítica dos fenômenos sociais e políticos: metodologia e fundamentação teórica. Revista Mal-estar e Subjetividade, 4(2), 329-348.

Sampaio. C. P. (2006). Algumas ideias sobre pesquisa em psicanálise. Jornal de Psicanálise, 39(70), 243-255.

Sauret, M-J. (2003). A pesquisa clínica em Psicanálise. Psicologia USP, 14(3), 89-104. 